\title{
Cerebral arterial air embolism after endobronchial electrocautery: a case report and review of the literature
}

Yu-Ping He ${ }^{1+}$, Yuan-Ling Liu ${ }^{2,3+}$, Xing-Lin Gao ${ }^{2,3}$ and Li-Hua Wang ${ }^{1 *}$

\begin{abstract}
Background: Endobronchial electrocautery is a common and safe therapeutic endoscopic treatment for malignant airway obstruction. Cerebral arterial air embolism (CAAE) is a rare but potentially fatal complication of endobronchial electrocautery.

Case presentation: We present the first case of cerebral arterial air embolism after endobronchial electrocautery. A 56-year-old male with a pulmonary tumour in the right upper lobe received repeated endobronchial electrocautery. During the procedure, he experienced unresponsiveness, hypoxemia and bradycardia, and he developed tetraplegia. Brain computed tomography showed several cerebral arterial air emboli with low-density spots in the right frontal lobe. He received hyperbaric oxygen therapy with almost full recovery, except for residual left-sided weakness.

Conclusions: General physicians should realize that CAAE may be a possible complication of endobronchial electrocautery. Several measures, including avoiding positive pressure, lowering ventilatory pressures if possible, avoiding advancing the bronchoscope to occlude the bronchus and using the non-contact technique, should be used to prevent this devastating complication.
\end{abstract}

Keywords: Air embolism, Bronchoscopy, Endobronchial electrocautery, Hyperbaric oxygen therapy

\section{Background}

Therapeutic endoscopic treatment may be considered for use in malignant airway obstruction, such as endobronchial electrocautery, argon plasma coagulation (APC), and thermal lasers. Electrocautery is a common and safe bronchoscopy technique. The main complications of electrocautery include bleeding and airway fire. Cerebral arterial air embolism is an extremely rare but potentially fatal complication of bronchoscopy. Azzola et al. [1] reported a frequency of $<0.02 \%$ of cerebral air embolism after bronchoscopy in their institution. Although cerebral

*Correspondence: wlh95070@163.com

†Yu-Ping He and Yuan-Ling Liu should be considered joint first author ${ }^{1}$ Department of Pulmonary and Critical Care Medicine, Yunfu People's Hospital, Huanshi Dong Lu No.120, Yuncheng DistrictYunfu 527300, China Full list of author information is available at the end of the article arterial air embolism has been shown to be a complication of APC and thermal laser treatments [2], it has never been reported in electrocautery. Herein, we described a patient who developed cerebral arterial air embolism (CAAE) after endobronchial electrocautery.

\section{Case presentation}

A 56-year-old male, who never smoked, was transferred to our hospital. Approximately 16 years prior, he had been diagnosed with lung cancer and received lung surgery and chemotherapy. Three years ago, he developed a cough and underwent three endobronchial electrocautery treatments in another hospital. As a result, the right middle lobe (RML) mass was debulked. With the diagnosis of the recurrence of right lung endobronchial adenocarcinoma, the patient was admitted for the fourth bronchoscopic thermal ablation procedure to relieve 
airway obstruction. Bronchoscopy revealed an endobronchial tumour emanating from the posterior segment of the right upper lobe (RUL) bronchus, causing complete obstruction of the bronchus (Fig. 1a). The patient was in the supine position without intravenous sedation. The tumour was debulked using endobronchial electrocautery, and blunt dissection of devitalized tissues with tooth forceps was performed (Fig. 1b, c). The electrocautery cut mode was set at an intensity of $40 \mathrm{~W}$, and the coagulation mode was set at an intensity of $30 \mathrm{~W}$ for a duration of $3 \mathrm{~s}$.

The bronchoscopy operation took approximately $30 \mathrm{~min}$ in total, including $15 \mathrm{~min}$ of endobronchial electrocautery therapy. Fifteen incinerations were performed. During the procedure, the patient showed no cough and no obvious bleeding. At the end of the operation, he suddenly became unresponsive, hypoxemic $\left(\mathrm{SpO}_{2}=88 \%\right)$ and bradycardic (heart rate $=58 / \mathrm{min}$ ). High-flow oxygen administration with a mask and fluid resuscitation were quickly performed. His heart rate and $\mathrm{SpO}_{2}$ recovered quickly, and his consciousness gradually improved 30 min later. However, he presented with obvious abnormal neurological symptoms, including slurred speech, right gaze and paralysis in both extremities. The muscle strength in the left limbs was $0 / 5$, while it was $2 / 5$ in the right limbs. His left Babinski sign was positive. Hypoglycaemia was excluded. Emergency brain computerized tomography $(\mathrm{CT})$ revealed the presence of rounded cerebral gas embolisms that were several millimetres in size and low-density spots in the right frontal lobe (Fig. 2).

Hyperbaric oxygen therapy $\left(\mathrm{HBO}_{2}\right)$ was initiated within $2 \mathrm{~h}$ after bronchoscopy. He was transferred to the intensive care unit. That night, he received another hyperbaric oxygen therapy. After this treatment, the patient experienced generalized tonic-clonic seizures that were aborted using phenytoin, phenobarbitone and sodium valproate. A repeated brain CT was performed $24 \mathrm{~h}$ after bronchoscopy and showed no signs of air embolism (Fig. 3). The patient received intensive rehabilitation. His mental status subsequently improved, but he still had mild left-sided hemiparesis with muscle strength of $3 / 5$ in the left upper limb and muscle strength of $4 / 5$ in the left lower limb.

\section{Discussion and conclusions}

CAAE is a rare but potentially fatal complication of both diagnostic and therapeutic bronchoscopy, and it is often iatrogenic [3]. Because knowledge about the aetiology of CAAE is limited, case reports are therefore important sources to obtain information [4]. To our knowledge, only four cases of CAAE after thermal ablation have been reported [5-8]. The profiles of the reported patients, the examination procedures undertaken, the treatments, and the outcomes are shown in Table 1 . This is the first reported case in the literature of CAAE developing after endobronchial electrocautery.

The possible mechanisms responsible for the development of CAAE during therapeutic bronchoscopy include the formation of a broncho-vascular fistula, the occlusion of a bronchus by bronchoscopy and paradoxical embolization [3, 4, 8, 9]. A broncho-vascular fistula can form due to inflammation or heat coagulation and mechanical destruction of the tumour and adjacent tissue $[7,10]$. In this case, electrocautery ablation of the tumour accompanied by mechanical debridement of the bronchus might have resulted in the formation of the broncho-vascular fistula $[1,11]$. Gas can enter the circulation through the fistula, and a gas embolism can easily enter a bronchovascular fistula if the internal airway pressure goes up with the bronchoscopy process or when the patient is accepting positive pressure ventilation, coughing or taking a deep breath during the procedure [7, 12-15]. Paradoxical embolization occurs when the gas migrates

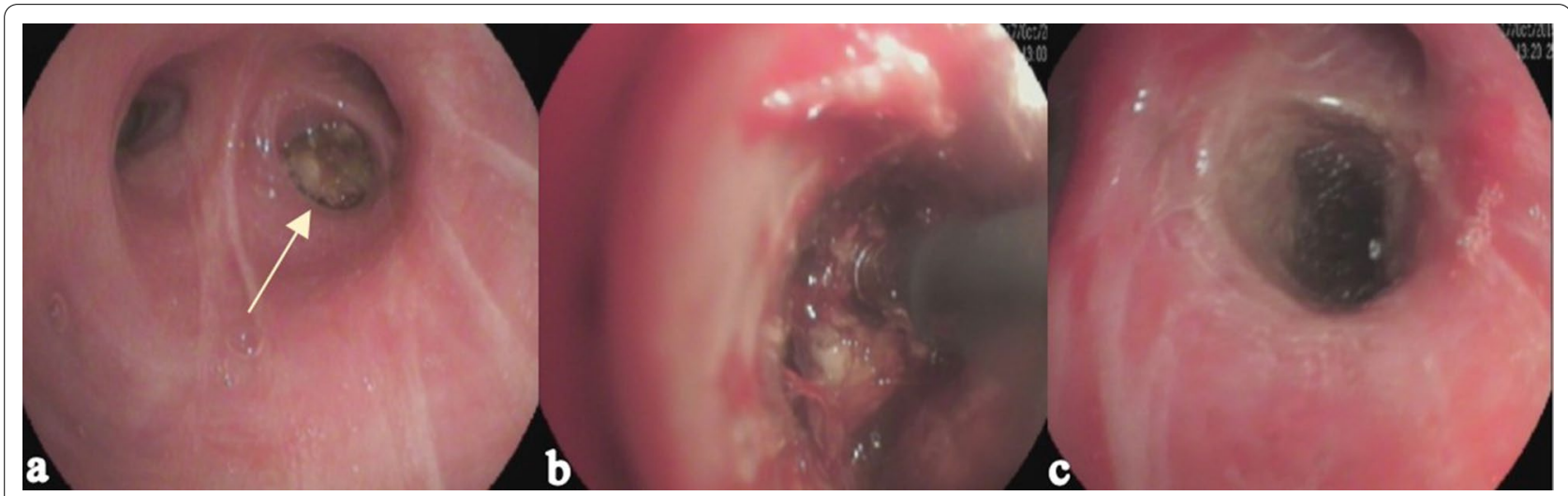

Fig. 1 The bronchoscopy showed that the posterior segment of the RUL bronchus was completely obstructed by the tumour (a, arrow). Endobronchial electrocautery was used to debulk the tumour (b). Bronchoscopy showed the posterior segment after ablation (c) 


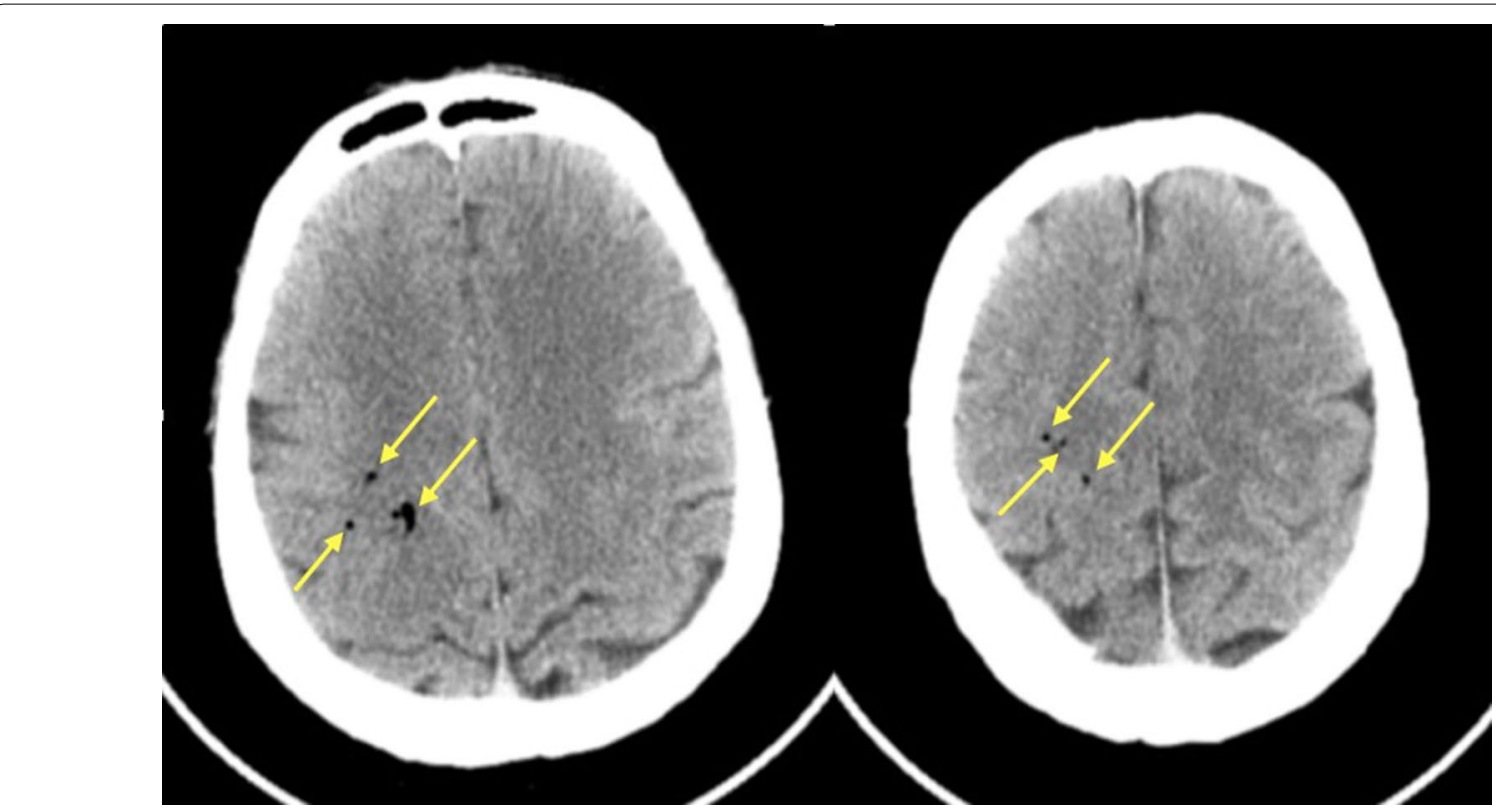

Fig. 2 The cerebral CT scan following bronchoscopy showed multifocal cerebral air embolisms in the right frontal lobe (arrows)

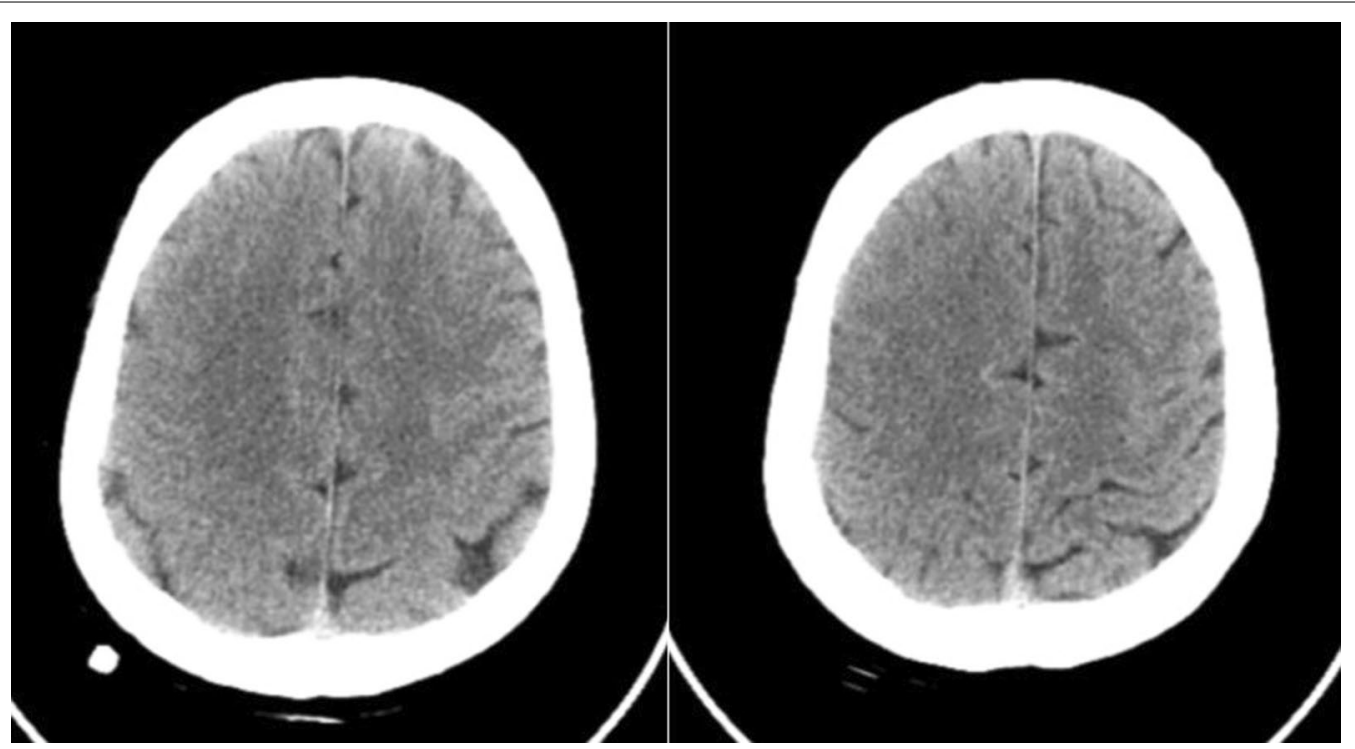

Fig. 3 The repeated cerebral CT scan performed $24 \mathrm{~h}$ after bronchoscopy demonstrated no signs of air embolism

from the venous circulation into the arterial system via an intracardiac shunt (patent foramen ovale)[16]. The air can be eliminated through diffusion into the alveoli, but if the capacity of the air exceeds $50 \mathrm{~mL}$, it easily enters the pulmonary veins $[16,17]$. In an animal study, FellerKopman et al. [10, 13] found that bronchoscopic thermal ablation with gas flow is associated with the occurrence of gas embolism in a dose-dependent manner, which is consistent with the fact that high flow of coolant gas can lead to vascular air embolism during the use of a contact probe [10]. Other possible risk factors for CAAE include patients with chronic obstructive pulmonary disease, a cavity inside the mass, lesions in the upper lobe, left lateral position, semi-recumbent position and bleeding $[1,7$, 18]. In this case, the tumour was located in the posterior segment of the right upper lobe, completely obstructing the bronchus. As the bronchial electrocautery continued, the pressure of the internal airway increased accordingly, 
Table 1 The profile of patients who developed CAAE after thermal ablation for endobronchial tumour

\begin{tabular}{|c|c|c|c|c|c|}
\hline Reference number & [5] & [6] & [7] & {$[8]$} & \\
\hline Author and year & $\begin{array}{l}\text { Osseiran et al } \\
2008\end{array}$ & $\begin{array}{l}\text { Mimy et al } \\
2011\end{array}$ & $\begin{array}{l}\text { Yasmeen et al } \\
2012\end{array}$ & $\begin{array}{l}\text { Kanchustambham et al } \\
2017\end{array}$ & This case \\
\hline \multicolumn{6}{|l|}{ Patient characteristic } \\
\hline Age & 64 & 48 & 88 & 68 & 56 \\
\hline Sex & Male & Male & Female & Male & Male \\
\hline \multicolumn{6}{|l|}{ Bronchoscopy } \\
\hline Procedure & APC & Thermocoagulation & APC & APC & Electrocautery \\
\hline Location & RML & LUL & RUL & Bronchus intermedius & RUL \\
\hline Positioning & N/A & N/A & Semi-recumbent & Semi-recumbent & Supine \\
\hline Bleeding & N/A & $>200 \mathrm{~mL}$ & $100 \mathrm{~mL}$ & Middle & Little \\
\hline Sedation & Midazolam & N/A & N/A & Fentanyl, Midazolam & $(-)$ \\
\hline \multicolumn{6}{|c|}{ Diagnosis, treatment and outcome of CAAE } \\
\hline Air bubbles in the CT images & $(+)$ & $(+)$ & $(+)$ & $(-)$ & $(+)$ \\
\hline Echocardiography shows air & $\mathrm{N} / \mathrm{A}$ & $(-)$ & N/A & $(-)$ & N/A \\
\hline Oxygen delivery & Intubation & Intubation, $\mathrm{HBO} 2$ & Intubation & $\mathrm{NBO}_{2}, \mathrm{HBO}_{2}$ & $\mathrm{HBO}_{2}$ \\
\hline Seizure & $(+)$ & $(+)$ & $(+)$ & $(+)$ & $(+)$ \\
\hline Outcome & Dead & Dead & Dead & Almost improved & Almost improved \\
\hline
\end{tabular}

$A P C$ argon plasma coagulation, $R M L$ right middle lobe, LUL left upper lobe, $R U L$ right upper lobe, $N / A$ not available, $H_{B} O_{2}$, hyperbaric oxygen, $N B O_{2}$ normobaric oxygen

which made it easier for air to enter the broncho-vascular fistula (Fig. 1). The increasing pressure of the bronchus during the endobronchial electrocautery procedure may have caused CAAE.

Iatrogenic CAAE can be caused by a broad range of procedures, such as central venous catheter, cardiopulmonary bypass, bronchoscopy, lung biopsy and Nd-YAG laser resection of tumours [4, 17]. In 1979, CAAE was suggested as a complication of transbronchoscopic lung biopsy [12], suggesting that CAAE should be considered a possible cause of neurological symptoms after any procedure with a possibility of CAAE. Clinicians should keep in mind the possibility of CAAE after endobronchial electrocautery.

The symptoms of CAAE develop suddenly and are the same as those of cerebral haemorrhage or thromboembolism, including hemiparesis, tetraplegia, seizures and coma with cardiovascular collapse. In some reported cases, the diagnosis of CAAE should be suspected when there is protracted recovery from sedation [8]. In this case, the patient lost consciousness. The symptoms of CAAE could be fatal or asymptomatic, indicating that it is important to consider the condition even without symptoms [4]. Because asymptomatic CAAE exists, the actual incidence is higher than that previously reported.

Imaging of the brain is useful to visualize air bubbles. In this case, $\mathrm{CT}$ was performed within $2 \mathrm{~h}$ of symptom onset, and air bubbles were observed in the right frontal lobe. CT may not always reveal the presence of air in the brain as bubbles may be reabsorbed quickly if there is a delay in imaging or if inadaptable window settings are used on non-contrast CT [19]. When the air bubble diameter is less than $1.3 \mathrm{~cm}$, it may not be detected by CT [15]. Kanchustambham et al. [8] reported that air bubbles cannot be visualized on CT images, thereby requiring the diagnosis to be made by exclusion. In this case, the repeated CT after $24 \mathrm{~h}$ showed no signs of air bubbles. Hence, CAAE cannot be ruled out through normal imaging. Acute infarction can be confirmed by MRI, which is more time-consuming than $\mathrm{CT}$ and might delay therapy. Transoesophageal echocardiography and precordial Doppler are used to detect intravenous and intracardiac air embolisms, and end-tidal carbon dioxide may be an early sign of air embolism $[9,13]$. As a result, clinical evaluation is still preferred for the assessment of CAAE [8].

Hyperbaric oxygen therapy is recommended as the most beneficial treatment for CAAEs $[9,16-18,20]$. The mechanisms of hyperbaric oxygen therapy for CAAE include reduced air volume, increased diffusion gradient out of the bubbles, reduction in cerebral oedema, decreased endothelial damage and promotion of restoration of distal blood flow [3, 6, 16, 20]. In some hospitals, $\mathrm{HBO}_{2}$ is not available due to the lack of a hyperbaric chamber or the inability to transport patients $[1,7,15,18]$. The time when the $\mathrm{HBO}_{2}$ treatment is started determines the outcome of the patients. Patients treated with $\mathrm{HBO}_{2}$ within 5 to $7 \mathrm{~h}$ from symptom onset have better outcomes [3, 4, 20]. However, there have been several reports of good outcomes in 
patients with delayed onset of treatment from $40 \mathrm{~h}$ to multiple days $[4,6,21]$. Our patient received the first $\mathrm{HBO}_{2}$ treatment within $3 \mathrm{~h}$ and the second $\mathrm{HBO}_{2}$ treatment within $24 \mathrm{~h}$, and no signs of air bubbles were observed on the repeated CT. The mortality in CAAE patients without $\mathrm{HBO}_{2}$ treatment is $93 \%$, while it is $7 \%$ with $\mathrm{HBO}_{2}$ treatment [21]. In conclusion, $\mathrm{HBO}_{2}$ should be initiated as soon as possible after the diagnosis of CAAE to reach the best effect. When there is no available $\mathrm{HBO}_{2}$, normobaric oxygen $\left(\mathrm{NBO}_{2}\right)$ should be administered as the most frequent non- $\mathrm{HBO}_{2}$ treatment $[8,18]$.

There are several different opinions on the position of the patient to prevent air embolism. Kanchustambham et al. [9] suggested using left lateral decubitus and the Trendelenburg position. The Trendelenburg position has been reported to reduce air bubbles entering into the brain [20]. However, some studies have revealed that the Trendelenburg position may worsen cerebral oedema, and patients should be placed flat and supine in cases of arterial air embolism $[4,16]$.

Patients suspected of being diagnosed with air embolism should be transferred to the intensive care unit for careful monitoring and management. Other treatments include endotracheal intubation, volume expansion and extracorporeal membrane oxygenation (ECMO) [9, 22]. Targeted temperature management (TTM) may be helpful to prevent the deterioration of cerebral function in cases of CAAE [23]. Other organs should be examined by echocardiography, electrocardiogram or other examinations when encountering a patient with CAAE because systemic air embolisms should be considered [24].

This is the first reported case of CAAE after endobronchial electrocautery. Physicians should realize that CAAE may be a possible complication of endobronchial electrocautery. Several measures, including avoiding positive pressure, lowering ventilatory pressures if possible, setting the flow to the lowest rate possible when using Nd-YAG or APC, avoiding advancing the bronchoscope to occlude the bronchus and using the non-contact technique, should be used to prevent this devastating complication.

\footnotetext{
Abbreviations

CAAE: Cerebral arterial air embolism; APC: Argon plasma coagulation; RML: Right middle lobe; LUL: Left upper lobe; RUL: Right upper lobe; N/A: Not available; $\mathrm{HBO}_{2}$ : Hyperbaric oxygen; $\mathrm{NBO}_{2}$ : Normobaric oxygen; $\mathrm{CT}$ : Computerized tomography; $\mathrm{HBO}_{2}$ : Hyperbaric oxygen therapy; ECMO: Extracorporeal membrane oxygenation; TTM: Targeted temperature management; Nd-YAG: Neodymium-doped Yttrium Aluminium Garnet.
}

\section{Acknowledgements}

The authors thank the patient and his families for approval for publication.

\section{Authors' contributions}

$Y P H$ and $Y L L$ were major contributors in writing the manuscript. XLG and LHW analysed, interpreted the patient data. All authors have read and approved the final manuscript.

\section{Funding}

No funding was received.

\section{Declarations}

\section{Ethics approval and consent to participate}

Not applicable.

\section{Consent for publication}

We confirm that we have obtained verbal consent to publish from the patient to report the individual patient's data and medical images. We have also now obtained written informed consent from the daughter of the patient, after he passed away.

\section{Competing interests}

The authors declare that they have no conflict of interest.

\section{Author details}

${ }^{1}$ Department of Pulmonary and Critical Care Medicine, Yunfu People's Hospital, Huanshi Dong Lu No.120, Yuncheng DistrictYunfu 527300, China. ${ }^{2}$ Department of Pulmonary and Critical Care Medicine, Guangdong Provincial People's Hospital, Guangdong Academy of Medical Sciences, Guangzhou, China. ${ }^{3}$ Guangdong Provincial Geriatrics Institute, Guangzhou, China.

Received: 12 October 2020 Accepted: 1 July 2021

Published online: 12 July 2021

\section{References}

1. Azzola A, von Garnier C, Chhajed PN, Schirp U, Tamm M. Fatal cerebral air embolism following uneventful flexible bronchoscopy. Respiration. 2010;80(6):569-72.

2. Du Rand IA, Barber PV, Goldring J, Lewis RA, Mandal S, Munavvar M, et al. British Thoracic Society guideline for advanced diagnostic and therapeutic flexible bronchoscopy in adults. Thorax. 2011;66(Suppl 3):iii1-21.

3. Murphy RP, Donnellan J. A high-pressure solution for a high-pressure situation: management of cerebral air embolism with hyperbaric oxygen therapy. Cureus. 2019;11(9):5559.

4. Hatling D, Hogset A, Guttormsen AB, Muller B. latrogenic cerebral gas embolism-a systematic review of case reports. Acta Anaesthesiol Scand. 2019;63(2):154-60.

5. Osseiran K, Barchfeld T, Dellweg D, Haidl P. Cerebral arterial gas embolism as complication during the therapeutic endobronchial use of argon plasma coagulation. Pneumologie. 2008;62(6):353-4.

6. Mimy Y, Nackers P. Clinical case of the month. Cerebral air embolism arising during a procedure of thermocoagulation of a bronchial epidermoid carcinoma in situ by fiberscopy. Rev Med Liege. 2011;66(2):64-8.

7. Shaw Y, Yoneda KY, Chan AL. Cerebral gas embolism from bronchoscopic argon plasma coagulation: a case report. Respiration. 2012;83(3):267-70.

8. Kanchustambham V, Reddy M, Saladi S, Patolia S. Cerebral air embolism as possible cause of stroke during therapeutic endobronchial application of argon plasma coagulation. Cureus. 2017;9(5):1255.

9. Kanchustambham V, Saladi S, Mehta K, Mwangi J, Jamkhana Z, Patolia S. Vascular air embolism during bronchoscopy procedures-incidence, pathophysiology, diagnosis, management and outcomes. Cureus. 2017;9(3):e1087.

10. Tellides G, Ugurlu BS, Kim RW, Hammond GL. Pathogenesis of systemic air embolism during bronchoscopic Nd:YAG laser operations. Ann Thoracic Surg. 1998;65(4):930-4.

11. Sigurdsson MI, Sigurdsson H, Hreinsson K, Simonardottir L, Gudbjartsson T. Bronchiovenous fistula causing bleeding and air embolism: an unusual complication of bronchoscopic tumor resection. Am J Respir Crit Care Med. 2011;183(5):681-2. 
12. Erickson AD, Irwin RS, Teplitz C, Corrao WM, Tarpey JT. Cerebral air embolism complicating transbronchoscopic lung biopsy. Ann Internal Med. 1979;90(6):937-8.

13. Feller-Kopman D, Lukanich JM, Shapira G, Kolodny U, Schori B, Edenfield $\mathrm{H}$, et al. Gas flow during bronchoscopic ablation therapy causes gas emboli to the heart: a comparative animal study. Chest. 2008;133(4):892-6.

14. Evison M, Crosbie PA, Bright-Thomas R, Alaloul M, Booton R. Cerebral air embolism following transbronchial lung biopsy during flexible bronchoscopy. Respir Med Case Rep. 2014;12:39-40.

15. Almas ET, Casserly B. Air embolism following bronchoscopy with fine needle aspiration: an unexpected complication. Respir Med Case Rep. 2018:25:228-32.

16. Fogelfeld K, Rana RK, Soo Hoo GW. Cerebral artery gas embolism following navigational bronchoscopy. J Intensive Care Med. 2018;33(9):536-40.

17. Cbt $C, L k L, A b M$. A patient with massive cerebral arterial air embolism. Med J Malays. 2019;74(3):226-8.

18. Maemura K, Kage H, Isago H, Takeshima H, Makita K, Amano Y, et al. Cerebral arterial air embolism after diagnostic flexible fiberoptic bronchoscopy: a case report and review of the literature. Case Rep Pulmonol. 2018;2018:7108215
19. Zakhari N, Castillo M, Torres C. Unusual cerebral emboli. Neuroimaging Clin N Am. 2016;26(1):147-63.

20. Cooper J. Treatment of endoscopy associated cerebral gas embolism. Am J Gastroenterol. 2018;113(12):1742-4.

21. Layon AJ. Hyperbaric oxygen treatment for cerebral air embolismwhere are the data? Mayo Clin Proc. 1991;66(6):641-6.

22. Reddy C, Majid A, Michaud G, Feller-Kopman D, Eberhardt R, Herth F, et al. Gas embolism following bronchoscopic argon plasma coagulation: a case series. Chest. 2008:134(5):1066-9.

23. Oh SH, Kang HD, Jung SK, Choi S. Implementation of targeted temperature management in a patient with cerebral arterial gas embolism. Ther Hypothermia Temp Manag. 2018;8(3):176-80.

24. Tsuji T, Sonobe S, Koba T, Maekura T, Takeuchi N, Tachibana K. Systemic air embolism following diagnostic bronchoscopy. Intern Med. 2017;56(7):819-21.

\section{Publisher's Note}

Springer Nature remains neutral with regard to jurisdictional claims in published maps and institutional affiliations.
Ready to submit your research? Choose BMC and benefit from:

- fast, convenient online submission

- thorough peer review by experienced researchers in your field

- rapid publication on acceptance

- support for research data, including large and complex data types

- gold Open Access which fosters wider collaboration and increased citations

- maximum visibility for your research: over $100 \mathrm{M}$ website views per year

At BMC, research is always in progress.

Learn more biomedcentral.com/submissions 